DOI: 10.34185/1991-7848.itmm.2020.01.014

\title{
МОДЕЛЮВАННЯ ВПЛИВУ СТРІЧКОВОГО ВКЛЮЧЕННЯ НА НАПРУЖЕНО-ДЕФОРМОВАНИЙ СТАН СФЕРИЧНОЇ ОБОЛОНКИ З ЕЛІПТИЧНИМ ОТВОРОМ
}

Гудрамович В. С. ${ }^{1)}$, чл.-кор. НАН України, д.т.н, Гарт Е. Л. ${ }^{2)}$, д.ф.-м.н, Марченко О. А. ${ }^{2)}$, асп.

1) Інститут технічної механіки НАН України та Державного космічного агентства України, Дніпро, Україна

2) Дніпровський національний університет імені Олеся Гончара, Дніпро, Україна

Ключові слова: сферична оболонка, еліптичний отвір, включення, внутрішній тиск, напружено-деформований стан, коефіцієнт концентрації напружень, метод скінченних елементів.

Розглянуто напружений стан тонкостінної ізотропної сферичної оболонки радіусу $R$, товщини $h$ з еліптичним отвором ( $a$ та $b$ - піввісі еліпсу), що підкріплюється оточуючим його стрічковим включенням 3 іншого, ніж основний матеріал оболонки, матеріалу ( $h_{0}$ - ширина включення). Вважається, що отвір закрито кришкою спеціальної конструкції, яка передає дію тільки перерізуючей сили [4]. Підкріплюючі елементи змодельовані вставками товщини $h$, що відповідає товщині оболонки; на границях включень задані умови жорсткого зчеплення. Оболонка знаходиться під дією рівномірного внутрішнього тиску інтенсивності $p$ (рис. 1).

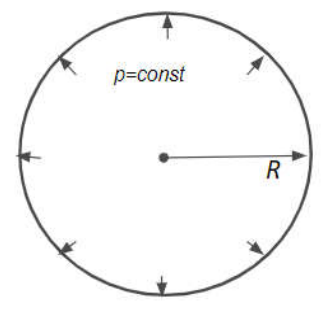

a)

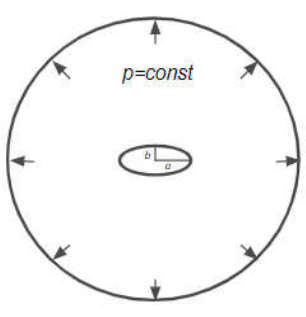

б)

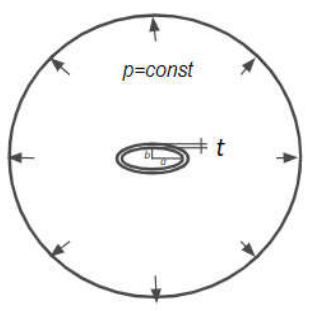

в)

Рисунок 1 - Геометрія та схема навантаження сферичної оболонки: а) без отвору;

б) з еліптичним отвором; в) з еліптичним отвором і стрічковим включенням

В варіаційній постановці задача про дослідження напруженодеформованого стану (НДС) оболонки зводиться до мінімізації функціоналу повної потенціальної енергії деформації системи [2] : 


$$
\begin{aligned}
& \quad \ni=\sum_{i=1}^{n}\left(\frac{D_{i}}{2} \iint\left[\left(k_{1 i}+\kappa_{2 i}\right)^{2}+2\left(1-\mu_{i}\right)\left(\kappa_{12 i}^{2}-\kappa_{1 i} k_{2 i}\right)\right] R d \phi d x+\frac{E_{i} \mathrm{~h}_{i}}{2\left(1-\mu_{i}^{2}\right)} \iint\left(\varepsilon_{1 i}^{2}+\right.\right. \\
& \left.\left.+2 \mu \varepsilon_{1 i} \varepsilon_{2 i}+\varepsilon_{2 i}^{2}+\frac{1-\mu_{i}}{2} \gamma_{i}^{2}\right) R d \phi d x-\iint\left(p_{x} u_{i}+\mathrm{p}_{\phi} v_{i}+\mathrm{p}_{z} w_{i}\right) R d \phi d x\right)
\end{aligned}
$$

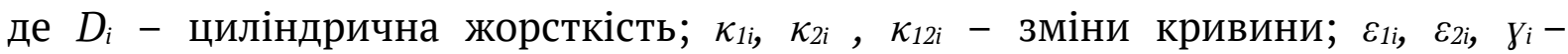
видовження і кут повороту; $\mu_{i}-$ коефіцієнт Пуассона; $E_{i}-$ модуль пружності ділянки; $R$ - радіус оболонки; $p_{x}, p_{y}, p_{z}$ - проекції вектору навантаження.

Числовий аналіз проведено за допомогою методу скінченних елементів при використанні оболонкових елементів та послідовності адаптованих сіток. Результати отримані для сферичної оболонки 3 такими параметрами: $R=2 M$, $h=0,001 R$. Менша піввісь еліптичного отвору $b=0,05 \mathrm{R}$. Досліджено наступні варіанти ширини включення $h_{0}: 0,1 b ; 0,2 b ; 0,3 b ; 0,4 b ; 0,5 b$. Для визначеності в розрахунках застосовано два види матеріалу з такими модулями пружності $E_{i}$ та коефіцієнтами Пуассона $\mu_{\mathrm{i}}: E_{1}=110$ ППа, $\mu_{1}=0,32, \quad E_{2}=210$ ГПа, $\mu_{2}=0,3 \quad 3$ відповідними їм границею міцності та умовною границею текучості: $\sigma_{\mathrm{B}}=400 M \Pi a, \sigma_{0,2}=280 M \Pi a, \sigma_{\mathrm{B}}=630$ MПa, $\sigma_{0,2}=375$ МПа [1]. Вибір матеріалів носить умовний характер. Внутрішній тиск $p=0,1$ МПа.

Для зручності аналізу введено коефіцієнт відносної жорсткості включення за формулою: $k=E_{\text {вкл }} / E_{\text {обол }}$, де $E_{\text {вкл }}-$ модуль пружності включення; $E_{\text {обол }}-$ модуль пружності матеріала оболонки.
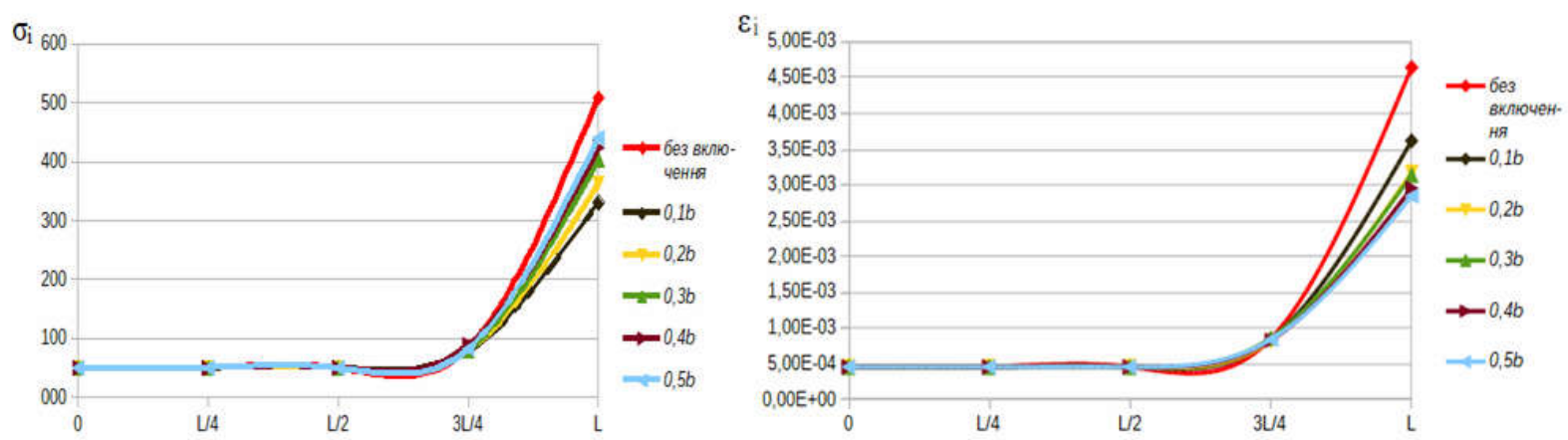

Рисунок 2 - Розподіл інтенсивностей напружень $\sigma_{\mathrm{i}}(\mathrm{MПа)} \mathrm{та} \mathrm{деформацій} \mathrm{єі} \mathrm{уздовж}$ $1 / 4$ меридіана оболонки в залежності від ширини $\mathrm{h}_{0}$ стрічкового включення $(\mathrm{k}>1)$

Розглянуто вплив «жорсткого» $(\mathrm{k}>1)$ та «м’якого» $(\mathrm{k}<1)$ включення навколо еліптичного отвору, розміри якого становлять $a / b=1,5$. При використанні «жорсткого» включення спостерігається збільшення інтенсивності напружень та зменшення інтенсивності деформацій в околі кінців більшої півосі 
Ministry of Education and Science of Ukraine

The National Metallurgical Academy of Ukraine, Dnipro, 17 - 19 March, 2020

еліптичного отвору (рис. 2); в разі «м'якого» включення відбувається зменшення інтенсивності напружень та збільшення інтенсивності деформацій в указаній зоні (рис. 3).
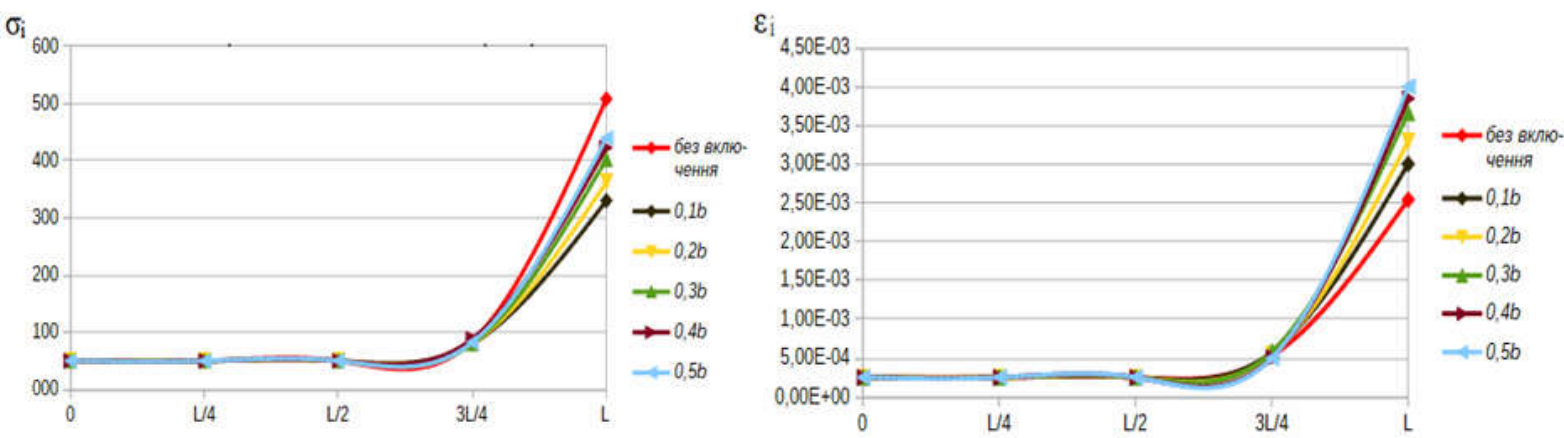

Рисунок 3 - Розподіл бі (MПа) та $\varepsilon_{\mathrm{i}}$ уздовж

$1 / 4$ меридіана оболонки в залежності від $h_{0}(\mathrm{k}<1)$

У табл. 1 подано результати, що характеризують зміну (у відсотках) максимальних значень інтенсивностей напружень $\sigma_{\mathrm{i}} \mathrm{i}$ деформацій $\varepsilon_{\mathrm{i}}$ в залежності від ширини стрічкового включення навколо еліптичного отвору $(a / b=1,5)$ у порівнянні з випадком оболонки без включень [3, 4].

Таблиця 1

\begin{tabular}{|c|c|c|c|c|c|}
\hline $\mathrm{h}_{0}$ & $0,1 b$ & $0,2 b$ & $0,3 b$ & $0,4 \mathrm{~b}$ & $0,5 b$ \\
\hline \multicolumn{6}{|c|}{ при k>1 } \\
\hline $\mathrm{KKH}$ & 14,4 & 12,64 & 12,51 & 11,76 & 11,33 \\
\hline$\Delta \sigma_{i}$ & $\uparrow 35 \%$ & $\uparrow 30 \%$ & $\uparrow 25 \%$ & $\uparrow 20 \%$ & $\uparrow 15 \%$ \\
\hline$\Delta \varepsilon_{\mathrm{i}}$ & $\downarrow 20 \%$ & $\downarrow 30 \%$ & $\downarrow 40 \%$ & $\downarrow 50 \%$ & $\downarrow 60 \%$ \\
\hline \multicolumn{6}{|c|}{ при k<1 } \\
\hline KKH & 6,58 & 7,23 & 8,04 & 8,43 & 8,77 \\
\hline$\Delta \sigma_{\mathrm{i}}$ & $\downarrow 40 \%$ & $\downarrow 25 \%$ & $\downarrow 20 \%$ & $\downarrow 15 \%$ & $\downarrow 10 \%$ \\
\hline$\Delta \varepsilon_{\mathrm{i}}$ & $\uparrow 20 \%$ & $\uparrow 30 \%$ & $\uparrow 32 \%$ & $\uparrow 35 \%$ & $\uparrow 40 \%$ \\
\hline
\end{tabular}

В результаті проведеного комп’ютерного моделювання встановлено суттєвий вплив включень на зміну концентрації параметрів НДС: у випадку «м’яких» включень слід вибирати включення меншої ширини 
International scientific and technical conference Information Technologies in Metallurgy and Machine building - ITMM 2020

$(0,1 b)$, що дозволяє знизити концентрацію напружень до 40\%; у випадку «жорстких» - більшої ширини $(0,5 b)$, що призводить до зменшення концентрації деформацій до $45 \%$.

Результати досліджень мають значення для проектування та оптимізації типових елементів деяких галузей техніки, зокрема, ракетно-космічної.

\section{Література}

1. Арзамасов Б. Н., Соловьева Т. В., Герасимов С. А. Справочник по конструкционным материалам. М.: Изд-во МГТУ им. Н. Э. Баумана, 2005. 640 с.

2. Балабух Л.И., Алфутов Н.А., Усюкин В.И. Строительная механика ракет. М.: Высш. шк., 1984. 392 c.

3. Гузь А. Н., Ч Чернышенко И. С., Чехов Вал. Н. и др. Методы расчета оболочек. В 5 т. Т. 1. Теория оболочек, ослабленных отверстиями. К.: Наук. думка, 1980. 636 с.

4. Савин Г. Н. Распределение напряжений около отверстий. К.: Наук. думка, 1968. 888 с.

\section{MODELING OF THE INFLUENCE OF TAPE INCLUSION ON THE STRESS-STRAINED STATE OF SPHERICAL SHELL WITH AN ELLIPTIC HOLE}

Hudramovych Vadym, Hart Eteri, Marchenko Oleh

Abstract. Shell structures have been widely used as carrying structures in many branches of industries. These types of structures combine high strength with small weight, therefore, to ensure the save operation of the structures, it is important for evaluation the strength and reliability. In most cases, shells used in real designs and have simple geometric shapes of surfaces (shells of rotation). Complex designs are usually a combination of these shell shapes. Investigation of the influence of local concentrators in view of holes for shells on the stress-strained state of the shells and methods of reducing the stress concentration in thin-walled shells of rotation is an urgent task of mechanics of a deformable solids. In this work a computer simulation of the behavior of a thin-walled spherical shell with an elliptical hole and tape inclusion is made. The finite element analysis of the influence of geometric and mechanical parameters for supporting elements of the hole, modeled by inclusions of material other than its shell material is carried out. We will note importance of such researches for design and optimization of construction for a number of industries, in particular, rocket-space technique. 
Keywords: spherical shell, elliptical hole, tape inclusions, internal pressure, stress-strain state, stress concentration coefficient, finite element method.

\section{References}

1. Arzamasov B.N., Solovieva T.V., Gerasimov S.A. Handbook of structural materials. Moscow: Publishing house of N.E. Bauman MSTU, 2005. 640 p. (in Russian).

2. Balabukh L.I., Alfutov N.A., Usyukin V.I. Structural mechanics of rockets. Moscow: Higher school, 1984. 392 p. (in Russian).

3. Guz A.N., Chernyshenko I.S. et al. Methods for calculating shells. In 5 vol. V. 1. Theory of shells weakened by holes. Kiev: Nauk. dumka, 1980. 636 p. (in Russian).

4. Savin G.N. Stress distribution around holes. Kiev: Naukova dumka, 1968. 888 p. (in Russian). 